\title{
Effect of composite post placement on bonding to root canal dentin using 1-step self-etch dual-cure adhesive with chemical activation mode
}

\author{
Masako OKUMA ${ }^{1}$, Masatoshi NAKAJIMA¹, Keiichi HOSAKA 1 , Shima ITOH${ }^{1}$, Masaomi IKEDA², Richard M. FOXTON ${ }^{3}$ \\ and Junji TAGAMI ${ }^{1,4}$ \\ ${ }^{1}$ Cariology and Operative Dentistry, Department of Restorative Sciences, Graduate School of Medical and Dental Sciences, Tokyo Medical and \\ Dental University, 1-5-45 Yushima, Bunkyo-ku, Tokyo 113-8549, Japan \\ ${ }^{2}$ Faculty of Dentistry School for Dental Technology, Tokyo Medical and Dental University, 1-5-45 Yushima, Bunkyo-ku, Tokyo 113-8549, Japan \\ ${ }^{3}$ Division of Conservative Dentistry, King's College London Dental Institute at Guy's, King's and St Thomas' Hospitals, King's College London, Floor \\ 25, London Bridge, London, SE1-9RT, UK \\ ${ }^{4} \mathrm{Global}$ Center of Excellence Program; International Research Center for Molecular Science in Tooth and Bone Diseases, Tokyo Medical and Dental \\ University, 1-5-45 Yushima, Bunkyo-ku, Tokyo 113-8549, Japan \\ Corresponding author, Masako OKUMA; E-mail: masaco0415@gmail.com
}

\begin{abstract}
This study evaluated the effect of composite post placement and/or light-irradiation of dual-cure resin composite on adhesion to root canal dentin using the chemical activation mode of a 1-step self-etch dual-cure adhesive. Post spaces were prepared in extracted premolars. Root canal spaces were applied with Unifil Core EM Self-Etching Bond, which was chemically-polymerized, and then filled with Unifil Core EM with or without the placement of composite post. Half the specimens of each group were light-cured for 10 seconds and the other half were chemically-cured in darkness for 30 minutes. After $24 \mathrm{~h}$ storage, microtensile bond strengths ( $\mu$ TBS) at the coronal and apical regions were measured. When light-curing, placement of the composite post significantly reduced the $\mu$ TBS to root canal dentin. On the other hand, when chemical-curing, there was no significant difference in $\mu$ TBS between with and without placement of the composite post.
\end{abstract}

Keywords: Microtensile bond strength, Dual-cure self-etch adhesive, Root canal dentin

\section{INTRODUCTION}

Resin composite build-ups with prefabricated fiber posts and a dentin bonding system have been widely used to restore endodontically treated teeth. The major advantage of this build-up method is the reduced incidence of root fracture because their elastic moduli are similar to dentin, leading to uniform stress distributions within a restored tooth ${ }^{1-5)}$. In the clinical situation where there is minimum removal of tooth substrate a direct resin build-up method is frequently used as this can be completed in one visit. On the other hand, when a tooth requires substantial reconstruction, it is not easy for clinicians to directly build-up it up in composite resin. Moreover, when the root canal is elliptical in cross section, it is difficult to obtain optimal adaptation between the root canal dentin and the prefabricated fiber post. Therefore, in this situation, an indirect resin build-up method may be the preferred option with chemical polymerization of the dual-cured adhesive and without light-irradiation to the adhesive agent, since the thickness of the lightpolymerized adhesive layer would interfere with the complete sitting of an indirect composite post \& core. However, it has been reported that when a dual-cure adhesive is chemically-polymerized, bond strengths to root canal dentin are lower compared with light activated polymerization ${ }^{6}$.

Indirect restorations require less luting resin composite than direct restorations. A reduction in the amount of luting resin composite would reduce contraction stress $^{7)}$, resulting in reduced de-bonding of the interface between luting resin composite and root canal dentin. On the other hand, the cavity configuration factor (C-factor), which represents the ratio of bonded to unbounded surface area, increases enormously when a composite post is inserted, because not only the root canal dentin surface but also the composite post surface has to be bonded ${ }^{8}$. It has been reported that the $\mathrm{C}$-factor in post-luted cavities may exceed 200; whereas, the C-factor of an intracoronal restoration is in the range of only 1 to $5^{8)}$. The restriction of free surfaces in such a deep and narrow root canal would affect adhesion to root canal dentin ${ }^{9}$. Bouillaguet et $\left.a l .{ }^{8}\right)$ indicated that when the $\mathrm{C}$-factor value is higher, a slower setting material may reduce stress at the bonded interface because the slow setting allows flow of the materials to relieve polymerization stress. The polymerization reaction of chemically-cured dual-cure resin composite is slower than lightpolymerization, leading to the development of lower contraction stress at the bonded surface ${ }^{10}$. On the other hand, a previous study without placement of composite post reported that chemically activated dualcure resin composite had lower bond strength to root canal dentin than light activation polymerization ${ }^{6}$. However, there have been very few studies on the evaluation of the bond strength to root canal dentin with and without placement of an indirect composite post and/or light-irradiation to luting dual-cure resin composite when a 1-step self-etch dual-cure adhesive is chemically-polymerized. 
Therefore, this study was designed to evaluate the effect of indirect composite post placement and/or lightirradiation on the adhesion of luting dual-cure resin composite to root canal dentin using a chemicallypolymerized 1-step self-etch dual-cure adhesive.

\section{MATERIALS AND METHODS}

\section{Specimen preparation}

Twelve single-rooted human premolar teeth, which had been recently extracted from adolescents for orthodontic reasons and stored frozen, were decoronated at the cementoenamel junction using a low speed diamond saw (Isomet, Buehler, Lake Bluff, IL, USA). Pulpal tissue was removed using endodontic files and the post spaces were then prepared using Gates-Glidden drills (Matsutani Seisakusho Co., Ltd, Takanezawa, Japan) and FibreKor drills (Pentron Corporation, Wallingford, CT, USA) in a low-speed handpiece under copious water cooling to a depth of $8 \mathrm{~mm}$ and a diameter of $1.5 \mathrm{~mm}$. After post space preparation, the root canals were rinsed with distilled water and dried with paper points. Prior to the bonding procedures, the external surfaces of the roots were built up with Clearfil AP-X resin composite (Kuraray Medical Inc, Tokyo, Japan) to make grips for testing and to prevent the effect of external light from the curing tip, which can pass through the thin portion of dentin wall to the adhesive resin during light curing procedures.

The materials used in this study and their chemical compositions are presented in Table 1. Generally, indirect composite post \& core is made of resin composite embedding fiber posts therefore the surface is composed of resin composite. In the current study, custom-made pre-polymerized posts $(8.0 \mathrm{~mm}$ long $\times 1.3 \mathrm{~mm}$ in diameter) fabricated with lower viscosity composite resin, Clearfil Majesty LV (Kuraray Medical Inc, Tokyo, Japan) were used as indirect composite posts. Since, the surface of indirect composite post \& core is clinically made of resin composites. The surfaces of the indirect composite posts were air-abraded with 50-70 $\mu \mathrm{m}$ alumina and coated with a silane coupling agent (Tokuso Ceramic Primer, Tokuyama Dental Corp., Tokyo, Japan), followed by gentle air blowing.

\section{Bonding procedure}

All twelve root canal spaces were applied with a 1-step self-etch dual-cure adhesive, Unifil Core EM SelfEtching Bond (GC Corp., Tokyo, Japan) using a microtip applicator (GC Corp., Tokyo, Japan) according to the manufacturer's instructions in the chemical activation mode, followed by injection of a dual-cure resin composite, Unifil Core EM (GC Corp., Tokyo, Japan), into the post space using an auto-mix cartridge and syringe with the placement of indirect composite post (Post-placement group) or none (No-post group) (Fig. 1). Half the specimens of each group were lightcured for 10 seconds at $>600 \mathrm{~mW} / \mathrm{cm}^{2}$ from a coronal direction using a conventional light source (Optilux 500, Demetron, Danbury, CT, USA), and the other half were chemically-cured in darkness for 30 minutes. The specimens were then stored in water at $37^{\circ} \mathrm{C}$ for $24 \mathrm{~h}$.

\section{Microtensile bond strength testing}

After $24 \mathrm{~h}$ storage, the bonded specimens were attached to the arm of a low speed diamond saw and eight slabs were serially cut perpendicular to the bonded interface under water cooling (Fig. 2). Each slab was then transversely sectioned at the middle part of the post into approximately $0.6 \times 0.6 \mathrm{~mm}$ thick beams. The cross-sectional area of each beam was measured using digital calipers (Mitutoyo CD15, Mitutoyo Co., Kawasaki, Japan). The ends of the beam and the remaining interface were glued onto a testing device in a table-top testing machine (EZ Test, Shimadzu Co., Kyoto, Japan) using cyanoacrylate glue (Zapit, DVA, Anaheim, CA, USA) and subjected to a tensile force at

Table 1 Materials used in the study

\begin{tabular}{lll}
\hline Material & Manufacturer & Composition \\
\hline $\begin{array}{l}\text { <Adhesive system> } \\
\text { Self-Etching Bond }\end{array}$ & $\begin{array}{l}\text { GC Corp., } \\
\text { Tokyo, Japan }\end{array}$ & $\begin{array}{l}\text { Liquid A: 4-MET, Dimethacrylate, Silicon } \\
\text { dioxide, Ethanol, Water, Photo initiator } \\
\text { Liquid B: Ethanol, Chemical initiator }\end{array}$ \\
\hline $\begin{array}{l}\text { Core material> } \\
\text { Unifil Core EM } \\
\text { (Universal shade) }\end{array}$ & GC Corp., & UDMA, Dimethacrylate, \\
\hline
\end{tabular}

Indirect resin composite post: Clearfil Majesty LV

(shade A2)
Kuraray Medical Inc., Tokyo, Japan
Barium glass, $\mathrm{SiO}_{2}$ filler, TEGDMA, Other

00001B
$<$ Silane coupling agent>

Tokuso Ceramic Primer
Tokuyama Dental Corp., Tokyo, Japan
Phosphate monomer, $\gamma$-methacyloxypropyl trimethoxysilane, Ethanol
338425 
a crosshead speed of $1 \mathrm{~mm} / \mathrm{min}$. The coronal four beams data were considered to represent the coronal portion of the post space corresponding to the coronal third of the root canal, and the apical four beams data were considered to represent the apical region corresponding to the middle third of the root canal.

\section{Fracture analysis}

After the specimens had fractured, both the resin side and dentin side of the fractured beams were mounted on brass tablets and gold sputter-coated. The fracture modes were observed using a scanning electron microscope (JSM-5310, JEOL, Tokyo, Japan). Fracture modes at the interface between the root canal dentin and the resin were classified into four categories: Cohesive failure in resin composite (more than $70 \%$ of the fracture area is within the resin), Adhesive failure (more than $70 \%$ of the fracture area is within the bonding resin), Cohesive failure in dentin (more than $70 \%$ of the fracture area is within the dentin) and Mixed failure (combination both type of cohesive failure and adhesive failure).

\section{Statistical analysis}

The bond strength data were analyzed using a threeway ANOVA (with/without post-placement, curing mode of the dual-cure resin composite, region of post space) and a two-way ANOVA $(\alpha=0.05)$. The failure mode data were analyzed using the chi-squared test. To avoid an accumulation of errors due to multiple comparisons, the significance level was modified by dividing it $(p<0.05)$ (Bonferroni Correction). Any value where $p<0.0083$ was considered significant.

\section{RESULTS}

The $\mu$ TBS data together with the results of the statistical analysis are presented in Table 2. Threeway and Two-way ANOVA's results are summarized in Tables 3 and 4. Three-way ANOVA revealed that there were significant differences in $\mu$ TBS among with/ without post-placement and curing mode of the dualcure resin composite, whereas there were no significant differences among the regions of the post space. There was no interaction between with/without post-

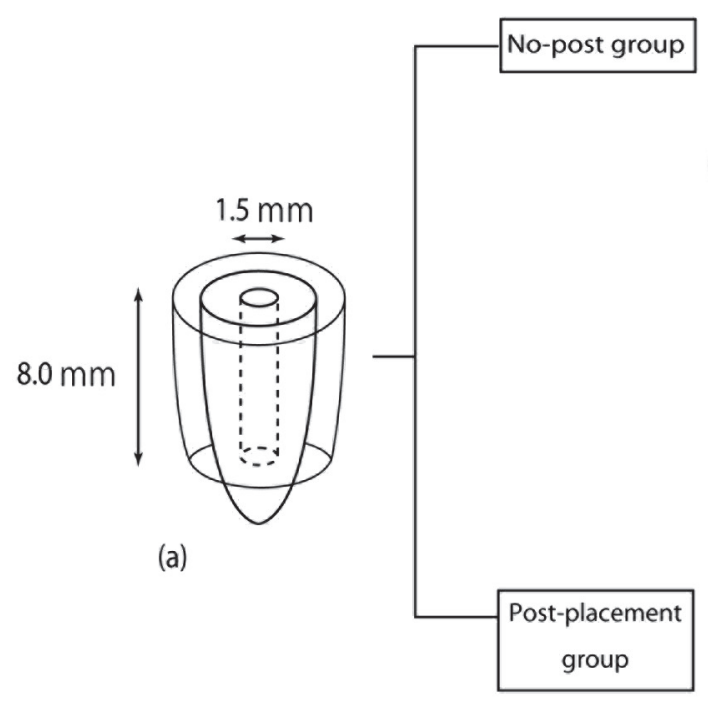

(d)

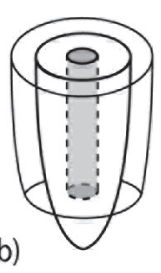

(b)

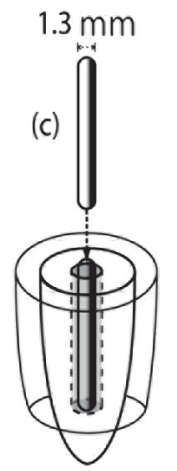

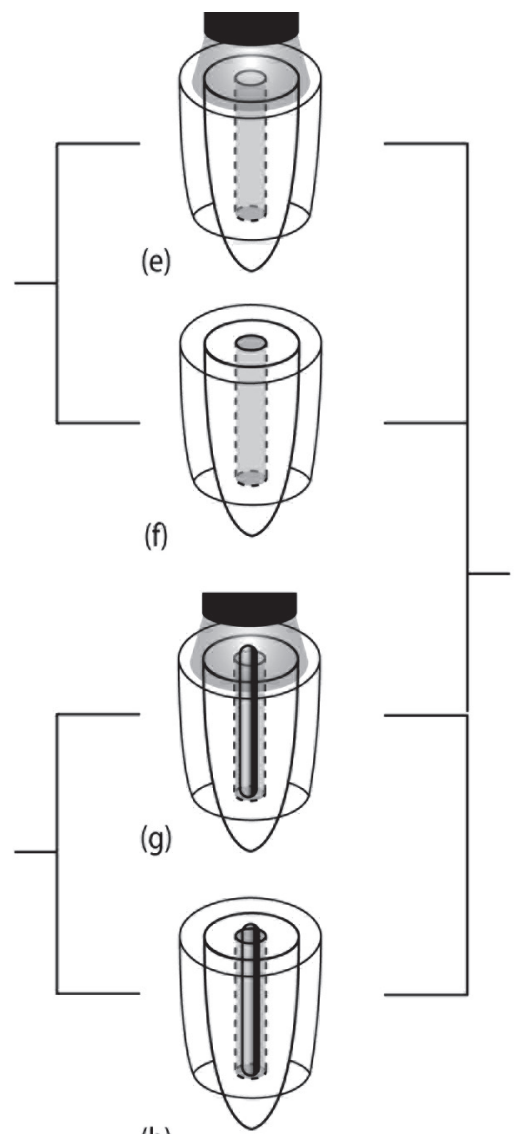

Water storage

for $24 \mathrm{~h}$

at $37^{\circ} \mathrm{C}$

Fig. 1 Preparation methods of no-post and post-placement samples.

(a) $8 \mathrm{~mm}$ deep post spaces prepared using $1.5 \mathrm{~mm}$ diameter drills.

(b) Post spaces were filled with dual-cure resin composite core material (Unifil Core EM; UC).

(c), (d) Post spaces were filled with UC and pre-polymerized indirect composite post inserted.

(e), (g) UC was light-cured for 10 seconds.

(f), (h) UC was chemically-cured in darkness for 30 minutes. 
placement, curing mode of the dual-cure resin composite and regions. An interaction between with/ without post-placement and curing mode was present, whereas there was no interaction between with/without post-placement and region, and between curing mode and regions.

Two-way ANOVA revealed that the $\mu$ TBS values were significantly different between the curing modes of the dual-cure resin composite in the post-placement group, whereas there was no significant difference between the curing modes in the no-post group. When the dual-cure resin composite was light-cured, the no- post group exhibited significantly higher bond strength compared with the post-placement group. However, when the dual-cure resin composite was chemicallycured, there were no significant differences between the post-placement group and the no-post group. Regardless of the post-placement and curing mode of the dual-cure resin composite, there was no significant difference in the $\mu$ TBS between the coronal and apical regions of the post space.

Fig. 3 presents the failure modes of the debonded specimens. In this study, there was no failure at the interface between composite post and luting resin

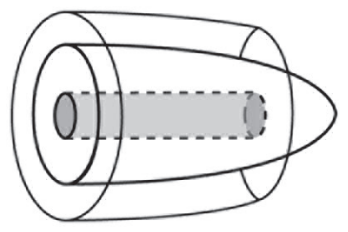

(a)

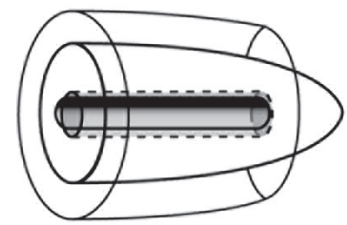

(b)

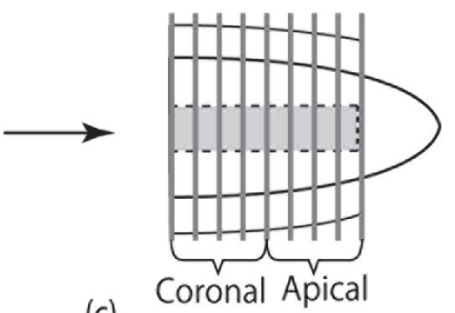

(c)

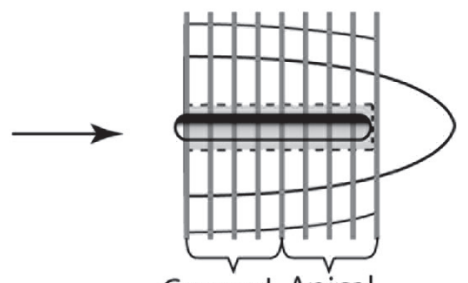

(d)

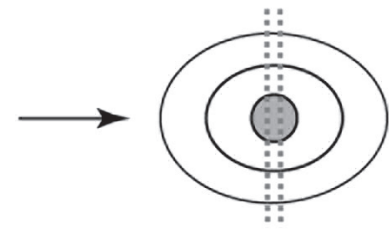

(e)

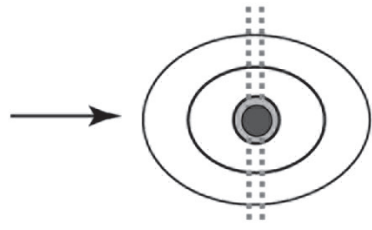

(f)

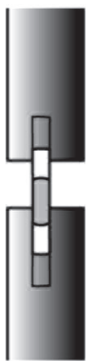

(g)

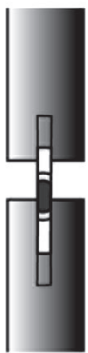

(h)

Fig. 2 Sectioning of specimens for microtensile bond test.

(a) No-post group.

(b) Post-placement group.

(c), (d) Each root was sliced into eight slabs (0.6 mm thick, four coronal \& four apical).

(e), (f) Each slab was cut centrally into a beam $(0.6 \times 0.6 \mathrm{~mm}$ thick).

(g), (h) Each beam was subjected to microtensile test (cross head speed; $1 \mathrm{~mm} / \mathrm{min}$ ).

Table 2 Microtensile bond strength to root canal dentin (MPa)

\begin{tabular}{|c|c|c|c|c|}
\hline & & \multicolumn{3}{|c|}{ Curing mode of luting dual-cure resin composite } \\
\hline & & Light-cure & & Chemical-cure \\
\hline \multirow{3}{*}{ Post-placement } & Coronal & $12.6(6.1)^{\mathrm{a}}$ & $p<0.05$ & $22.3(12.4)^{\mathrm{a}}$ \\
\hline & & $\mathrm{NS}$ & & NS \\
\hline & Apical & $8.6(5.8)^{\mathrm{A}}$ & $p<0.05$ & $23.6(12.5)^{\mathrm{A}}$ \\
\hline \multirow{3}{*}{ No-post } & Coronal & $22.1(11.6)^{b}$ & NS & $22.9(13.1)^{\mathrm{a}}$ \\
\hline & & $\mathrm{NS}$ & & NS \\
\hline & Apical & $18.6(9.2)^{\mathrm{B}}$ & NS & $24.6(8.7)^{\mathrm{A}}$ \\
\hline
\end{tabular}

All values are mean (SD) $(n=12)$.

Same superscript lower- or upper-case letters indicate no significant differences in the columns $(p>0.05)$.

$\mathrm{NS}=$ no significant difference $(p>0.05)$. 
composite. The chi-square test revealed no significant differences in the failure modes among the groups $(p>0.0083)$.

\section{DISCUSSION}

Using adhesive systems with resin composite material has been found to be advantageous in improving post \& core retention $^{11)}$ and fracture resistance of the restored tooth $^{12,13)}$. The bond strengths at both the post-resin and resin-dentin interfaces are important factors that will influence the clinical success of endodonticallytreated teeth built up with resin composite ${ }^{14)}$. In the present study, failures at the resin-dentin interface were found, but the failures at the post-resin interface were not present. These results indicate that the bond strengths of post-resin interfaces were higher than

Table 3 Results of statistical analysis by three-way ANOVA

\begin{tabular}{|c|c|c|c|c|c|c|}
\hline & & Sum of squares & $d f$ & Square mean & $\mathrm{F}$ & Sig. \\
\hline \multirow[t]{3}{*}{ Main factors } & Post-placement & 668.9 & 1 & 668.9 & 6.320 & 0.014 \\
\hline & Curing mode & $1,479.5$ & 1 & $1,479.5$ & 13.978 & 0.000 \\
\hline & Regions & 30.7 & 1 & 30.7 & 0.290 & 0.592 \\
\hline \multirow[t]{3}{*}{2 -way interaction } & Post-placement*Curing mode & 478.0 & 1 & 478.0 & 4.516 & 0.036 \\
\hline & Post-placement*Regions & 0.8 & 1 & 0.8 & 0.008 & 0.928 \\
\hline & Curing mode*Regions & 162.8 & 1 & 162.8 & 1.538 & 0.218 \\
\hline 3-way interaction & Post-placement*Curing mode* Regions & 0.0 & 1 & 0.0 & 0.000 & 0.989 \\
\hline Error & & $9,314.8$ & 88 & 105.8 & & \\
\hline Total & & $48,278.4$ & 96 & & & \\
\hline
\end{tabular}

Table 4 Results of statistical analysis by two-way ANOVA

\begin{tabular}{|c|c|c|c|c|c|c|}
\hline \multicolumn{2}{|c|}{ Post-placement group } & \multirow{2}{*}{$\begin{array}{c}\text { Sum of squares } \\
1,819.7\end{array}$} & \multirow{2}{*}{$\frac{d f}{1}$} & \multirow{2}{*}{$\begin{array}{c}\text { Square mean } \\
1,819.7\end{array}$} & \multirow{2}{*}{$\frac{\mathrm{F}}{19.118}$} & \multirow{2}{*}{$\begin{array}{c}\text { Sig. } \\
0.000\end{array}$} \\
\hline Main factors & Curing mode & & & & & \\
\hline & Regions & 20.9 & 1 & 20.9 & 0.220 & 0.642 \\
\hline Interaction & Curing mode*Regions & 83.3 & 1 & 83.3 & 0.875 & 0.355 \\
\hline Error & & $4,188.0$ & 44 & 95.2 & & \\
\hline Total & & $19,600.8$ & 48 & & & \\
\hline \multicolumn{7}{|c|}{ No-post group } \\
\hline \multirow[t]{2}{*}{ Main factors } & Curing mode & 137.8 & 1 & 137.8 & 1.183 & 0.283 \\
\hline & Regions & 10.6 & 1 & 10.6 & 0.091 & 0.764 \\
\hline Interaction & Curing mode*Regions & 79.6 & 1 & 79.6 & 0.683 & 0.413 \\
\hline Error & & $5,126.8$ & 44 & 116.5 & & \\
\hline Total & & $28,677.6$ & 48 & & & \\
\hline \multicolumn{7}{|c|}{ Light-cured group } \\
\hline \multirow[t]{2}{*}{ Main factors } & Regions & 167.4 & 1 & 167.4 & 2.315 & 0.135 \\
\hline & Post-placement & $1,138.9$ & 1 & $1,138.9$ & 15.748 & 0.000 \\
\hline Interaction & Regions*Post-placement & 0.6 & 1 & 0.6 & 0.008 & 0.929 \\
\hline Error & & $3,182.0$ & 44 & 72.3 & & \\
\hline Total & & $15,987.5$ & 48 & & & \\
\hline \multicolumn{7}{|c|}{ Chemically-cured group } \\
\hline \multirow[t]{2}{*}{ Main factors } & Regions & 26.1 & 1 & 26.1 & 0.187 & 0.667 \\
\hline & Post-placement & 8.0 & 1 & 8.0 & 0.057 & 0.812 \\
\hline Interaction & Regions*Post-placement & 0.3 & 1 & 0.3 & 0.002 & 0.963 \\
\hline Error & & $6,132.8$ & 44 & 139.4 & & \\
\hline Total & & $32,290.9$ & 48 & & & \\
\hline
\end{tabular}


(a)

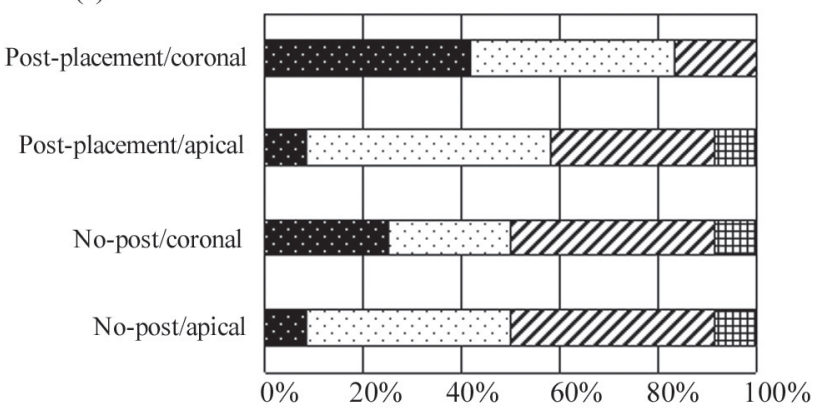

(b)

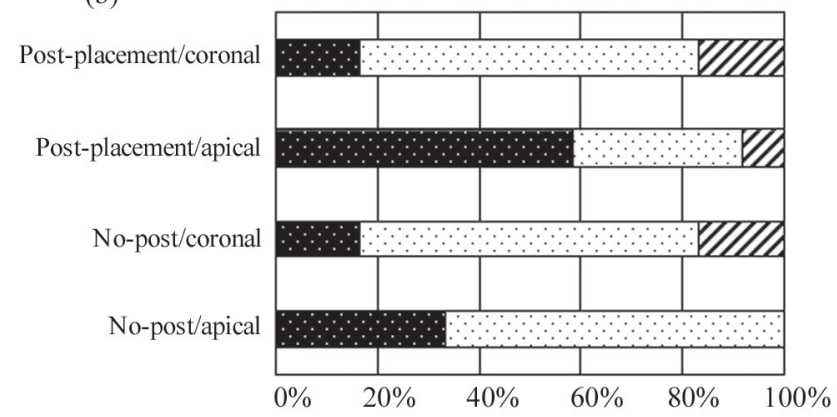

Cohesive failure within resin Adhesive failure

$\square$ Mixed adhesive/cohesive failure at resin/dentin interface

曲 Cohesive failure within dentin

Fig. 3 Failure modes of light-cured and chemically-cured specimens.

(a) Percentage of failure modes (cohesive failure within resin, adhesive failure, mixed adhesive/cohesive failure at resin/dentin interface, and cohesive failure within dentin) with light-curing of the luting dual-cure resin composite.

(b) Percentage of failure modes (cohesive failure within resin, adhesive failure, and mixed adhesive/cohesive failure at resin/dentin interface) with chemical-curing of the luting dual-cure resin composite.

those of resin-dentin interfaces, therefore the results of $\mu \mathrm{TBS}$ in all groups would represent their bonding abilities to root canal dentin using a 1-step self-etch dual-cure adhesive with chemical activation mode. In addition, for all the groups, there were no significant differences in the $\mu$ TBS between the coronal and apical regions. These results when the dual-cure adhesive was chemically activated are in agreement with a previous study using light activation mode of dual-cure adhesive $^{15)}$. Therefore, it is indicated that the curing modes of self-etch dual-cure adhesive does not affect the regional bond strengths to root canal dentin.

Polymerization shrinkage creates contraction stresses in resin composite, which were found to be a major cause leading to adhesive failure of composite restorations ${ }^{16,17)}$. The magnitude of shrinkage was found to be mainly dependent upon the resin volume ${ }^{18)}$. When a composite post is inserted into a post cavity, it is expected that a reduction in the amount of luting resin composite would result in less contraction stress ${ }^{7}$. However, in the present study, when the luting dualcure resin composite was light-cured, the bond strength of the post-placement group was significantly lower than that of the no-post group. Although the placement of a composite post can thin the luting resin composite layer, it would result in a reduction of free surfaces with very high C-factor values ${ }^{19-21)}$. It has been demonstrated that a higher $\mathrm{C}$-factor reduced the bond strength at the interface due to greater contraction stress $^{22)}$. On the other hand, the no-post group used a larger volume of dual-cure resin composite, however the thick resin layer might partially compensate for the high contraction stress by increasing the unboundedfree surface area and permitting some stress release by resin flow during polymerization ${ }^{9}$. Therefore, the reduction in the $\mu$ TBS of the post-placement group might have been due to fewer free surface areas of luting resin composite and an increase in the $\mathrm{C}$-factor values because of post placement.

Furthermore, the polymerization process would also affect the distribution of contraction stresses in resin composite. With regards to the post-placement group in the present study, light-curing of the dualcure resin composite produced significantly lower $\mu$ TBS than chemical-curing. Light-curing of the dual-cured resin composite would result in contraction stresses reaching higher values because the time for stress relief by flow would be limited ${ }^{23)}$. It has been demonstrated that the higher contraction stresses generated in dual-cure resin subjected to lightactivation may lead to higher marginal leakage at the enamel/cement interface ${ }^{23)}$. Therefore, rapid curing of dual-cure luting resin composite with light-irradiation would cause a reduction in the bond strength to root canal dentin. In addition, the chemical activation mode to dual-cure adhesive used in this study might have strongly affected the results because the bonding layer may not have been completely polymerized when the luting resin composite was polymerized by lightirradiation, leading to adhesive failure.

In contrast, when the luting dual-cure resin composite was chemically-cured, placement of the composite post did not affect the $\mu$ TBS to root canal dentin. Since the progress of curing is relatively slow for chemically cured materials, there is less stress caused by polymerization shrinkage ${ }^{24)}$. In addition, a slow polymerizing resin composite would allow greater relief of shrinkage stresses by the resin flow, because of 
the prolonged gelation time ${ }^{9}$. Chemical-curing of the luting resin composite may have therefore prevented debonding of the resin composite-root canal dentin interface even when the C-factor was higher as a result of composite post placement.

It can be concluded in this study that using the chemical activation mode of dual-cure adhesive, composite post placement and/or light-irradiation of the luting resin composite did not affect regional $\mu$ TBS to root canal dentin. When the luting dual-cure resin composite was light-cured, placement of the composite post significantly reduced the $\mu \mathrm{TBS}$ of the dual-cured adhesive when it was chemically- polymerized. On the other hand, when the luting dual-cure resin composite was chemically-cured, post did not affect the $\mu$ TBS to root canal dentin. When the dual-cure adhesive was chemically-cured, adhesion to root canal dentin was dependent upon post placement and/or mode of polymerization of the luting dual-cure resin composite.

\section{ACKNOWLEDGMENTS}

This work was partially supported by a grant from the Japanese Ministry of Education, Global Center of Excellence (GCOE) Program, "International Research Center for Molecular in Tooth and Bone Diseases".

\section{REFERENCES}

1) Isidor $F$, Odman $P$, Brondum $K$. Intermittent loading of teeth restored using prefabricated carbon fiber posts. Int $\mathrm{J}$ Prosthodont 1996; 9: 131-136.

2) Mannocci F, Ferrari M, Watson TF. Intermittent loading of teeth restored using quartz fiber, carbon-quartz fiber, and zirconium dioxide ceramic root canal posts. J Adhes Dent 1999; 1: 153-158.

3) Pegoretti A, Fambri L, Zappini G, Bianchetti M. Finite element analysis of a glass fiber reinforced composite endodontic post. Biomaterials 2002; 23: 2667-2682.

4) Akkayan B, Gulmez T. Resistance to fracture of endodontically treated teeth restored with different post systems. J Prosthet Dent 2002; 87: 431-437.

5) Fokkinga WA, Kreulen CM, Vallittu PK, Creugers NH. A structured analysis of in vitro failure loads and failure modes of fiber, metal and ceramic post-and-core systems. Int J Prosthodont 2004; 17: 476-482.

6) Foxton RM, Nakajima M, Tagami J, Miura H. Bonding of photo and dual-cure adhesives to root canal dentin. Oper Dent 2003; 28: 543-551.

7) Braga RR, Boaro LC, Kuroe T, Azevedo CL, Singer JM. Influence of cavity dimensions and their derivatives (volume and ' $\mathrm{C}$ ' factor) on shrinkage stress development and microleakage of composite restorations. Dent Mater 2006; 22: $818-823$.
8) Bouillaguet S, Troesch S, Wataha JC, Krejci I, Meyer JM, Pashly DH. Microtensile bond strength between adhesive cements and root canal dentin. Dent Mater 2003; 19: 199205.

9) Tay FR, Loushine RJ, Lambrechts P, Weller RN, Pashly DH. Geometric factors affecting dentin bonding in root canals: a theoretical modeling approach. J Endod 2005; 31: 584-589.

10) Feilzer AJ, De Gee AJ, Davidson CL. Setting stresses in composites for two different curing modes. Dent Mater 1993; 9: $2-5$.

11) Sen D, Poyrazoglu E, Tuncelli B. The retentive effects of pre-fabricated posts by luting cements. J Oral Rehabil 2004; 31: 585-589.

12) Lui JL. Composite resin reinforcement of flared canals using light-transmitting plastic posts. Quintessence Int 1994; 25: 313-319.

13) Mendoza DB, Eakle WS, Kahl EA, Ho R. Root reinforcement with a resin-bonded preformed post. J Prosthet Dent 1997; 78: 10-14.

14) Goodacre CJ, Bernal G, Rungcharassaeng K, Kan JY. Clinical complications in fixed prosthodontics. J Prosthet Dent 2003; 90: 31-41.

15) Aksornmuang J, Nakajima M, Foxton RM, Tagami J. Effect of prolonged photo-irradiation time of three self-etch systems on the bonding to root canal dentine. J Dent 2006; 34: 389-397.

16) Davidson CL, Feilzer AJ. Polymerization shrinkage and polymerization shrinkage stress in polymer-based restoratives. J Dent 1997; 25: 435-440.

17) Ferracane JL, Mitchem JC. Relationship between composite contraction stress and leakage in Class $\mathrm{V}$ cavities. Am J Dent 2003; 16: 239-243.

18) Braga RR, Ballester RY, Ferracane JL. Factors involved in the development of polymerization shrinkage stress in resincomposite: A systematic review. Dent Mater 2005; 21: 962 970.

19) Feilzer AJ, De Gee AJ, Davidson CL. Setting stress in composite resin in relation to configuration. J Dent Res 1987; 66: 1636-1639.

20) Alster D, Feilzer AJ, De Gee AJ, Davidson CL. Polymerization contraction stress in thin resin composite layers as a function of layer thickness. Dent Mater1997; 13: 98-102.

21) Laughlin GA, Williams JL, Eick JD. The influence of system compliance and sample geometry on composite polymerization shrinkage stress. J Biomed Mater Res 2002; 63: $671-678$

22) Choi KK, Ryu GJ, Choi SM, Lee MJ, Park SJ, Ferracane JL. Effect of cavity configuration on composite restoration. Oper Dent 2004; 29: 462-469.

23) Braga RR, Ferracane JL, Condon JR. Polymerization contraction stress in dual-cure cements and its effect on interfacial integrity of bonded inlays. J Dent 2002; 30: 333340.

24) Hayashi M, Ebisu S. Key factor in achieving firm adhesion in post-core restorations. Jpn Dent Sci Rev 2008; 44: 22-28. 